\title{
Perceived Stigmatization of Children with Speech-Language Impairment and Their Parents
}

\author{
Georg Macharey Waldemar von Suchodoletz \\ Department of Developmental Disorders, Clinic of Child and Adolescent Psychiatry, Psychosomatics and \\ Psychotherapy, Ludwig Maximilian University, Munich, Germany
}

\section{Key Words}

Perceived stigmatization - Speech-language impairment • Behavioral problems

\begin{abstract}
Objective: Developmental disorders in childhood are generally assumed to have stigmatizing effects. The goal of the present study was to assess whether parents of children with speech-language impairment perceive stigmatization of their child or themselves and which variables influence the degree of negative labeling. Subjects and Methods: The study was based on 362 questionnaires completed by parents of children with speech-language impairment. The questionnaires concerned perceived stigmatization by other children, other adults and family members as a result of the child's developmental problems. Results: In our sample, about $50 \%$ of the parents reported negative labeling of their child and about 30\% felt they were involved in the stigmatizing process. Parents whose children also had behavioral problems more often reported negative labeling than parents whose children did not. Conclusion: The findings suggest that parents of children with speech-language disorders often perceive stigmatization of their children or themselves. In counseling such families, professionals should therefore address stigmatization and its consequences as a separate and important issue. Copyright $\odot 2008$ S. Karger AG, Basel
\end{abstract}

\section{KARGER \\ Fax +41613061234 E-Mail karger@karger.ch} www.karger.com
(C) 2008 S. Karger AG, Base

$1021-7762 / 08 / 0605-0256 \$ 24.50 / 0$

Accessible online at:

www.karger.com/fpl

\section{Introduction}

About $50 \%$ of children with developmental language disorders also have emotional, behavioral or social difficulties (or some combination of these), a rate which is 3 times that seen in children without such impairments [1]. The most frequently reported psychopathology is externalizing behavior, such as hyperactivity, inattention, impulsivity, conduct disorders and aggression $[2,3]$. Also reported are difficulties of an internalizing nature, for example low self-esteem, depression and anxiety [4-6]. Some studies indicate that children with language disorders tend to have poorer social skills, be withdrawn in social interactions, have less prosocial behavior and be less integrated into peer groups than children without language impairments. Furthermore, these children have been found to have fewer friends, be invited less frequently to take part in social activities and be liked less by others $[7,8]$.

The importance of psychiatric disorders in children with developmental language disorders becomes even more apparent when the frequent persistence of emotional and behavioral difficulties into adulthood is considered [9]. Moreover, in a 14-year follow-up study from age 5 to 19 the prevalence of psychiatric disorders actually increased over time [10]. The appearance and augmentation of psychosocial problems in children with language disorders is thought to be at least partially a consequence of stigmatization $[4,11]$. 
The concept of stigmatization was introduced in social science by Goffman in 1963 [12]. A stigma arises as a product of four social processes. First, people distinguish and label human differences. Second, dominant cultural beliefs link labeled persons to negative stereotypes. Third, labeled persons are placed in distinct categories which leads to a separation into 'us' and 'them'. Fourth, labeled persons experience status loss and discrimination [13]. Link and Phelan [13] state that 'stigma exists when a person is identified by a label that sets the person apart and links the person to undesirable stereotypes that result in unfair treatment and discrimination'.

Goffman's stigma concept inspired an extensive discussion about the consequences of stigmatization for adults with mental illness. Numerous studies have shown that stigmatization can lead to depression, reduced selfesteem and social isolation, and that negative outcomes of mental illness may result more from stigmatization than from the primary disorder [14-17]. In contrast to the wide range of studies on the impact of stigmatization in adults with mental illness, there have been few such studies in children with developmental disorders.

Empirical studies involving stigmatized children are rare, and most have focused on the reactions of nonstigmatized children to stigmatized children. Britten et al. [18] reported that in children with epilepsy a high score on an index of social visibility at school was significantly associated with poorer educational outcomes. In the authors' view stigmatizing processes had affected the outcome. Stigmatization in children is occasionally discussed in the context of bullying [19-21]. Scheithauer et al. [22] found that children with cognitive or communication disorders, those with poor social skills and those who attended special schools were at a higher risk of being bullied than their unaffected peers. Klicpera and Klicpera [23] showed that low self-esteem, depressive mood, social isolation and a feeling of helplessness are frequent consequences of victimization at school.

Not only can a stigma itself induce stigmatizing effects, so can negative expectations. Harris et al. [24] examined interactions between children with and without conduct disorders (68 pairs of unacquainted boys in grades $2-6$ ). The normal boys were either told that their partner had a behavioral problem or given no information in this regard. The expectation of difficult behavior had a negative impact on the interaction process.

The involvement of parents in the stigmatization process is occasionally mentioned in the literature but has seldom been the object of research. Lücke and Knölker [25] reported that $25 \%$ of the participating parents felt labeled as a result of their child being a patient in a hospital for child and adolescent psychiatry. Furthermore, Phelan et al. [26] found that in some cases parents of adolescents and adults with mental illnesses perceive themselves as being avoided because of their relative's hospitalization.

From the studies cited it therefore appeared that children with speech-language disorders are at risk of being stigmatized because of their disabilities and hence discriminated against by other members of society. Furthermore, there was evidence that their parents are occasionally involved in the stigmatizing process. The goal of the present study was to assess whether parents of children with speech-language disorders perceive stigmatization of their child or themselves as a result of the child's developmental disability and what personal and environmental factors have an impact on the extent of perceived labeling.

\section{Methods}

\section{Sample}

The subjects were parents with a child who was attending a preschool or school for children with speech-language impairment or who was having speech-language therapy. Seven preschools, 4 schools and 7 therapists participated in the study. The parents were asked to complete a questionnaire about the family's sociodemographic situation, the child's disabilities and behavior, and perceived stigmatization and support related to their child's disabilities. They received the questionnaire together with a stamped, addressed envelope from their child's teacher or therapist. They were asked to complete the questionnaire at home und send it to us anonymously. Most of the questionnaires were filled in by the mother (mother: $73 \%$; both parents: $16 \%$; father: $6 \%$; others: $5 \%$ ).

Of the 877 parents who received a questionnaire, 386 responded (return rate of $44 \%$ ). Sixteen respondents were then excluded because of missing data on more than $10 \%$ of the stigmatization items. Most children were between 4 and 11 years old, with only 8 being younger or older. The data for these 8 parent-child pairs were excluded from the study. Therefore, the final sample consisted of data for 362 children.

Table 1 shows the characteristics of the sample. Two thirds of the children were boys. The classification of the child's disabilities is based on the most serious impairment as rated by the parent. Parents judged the severity of their child's language and learning problems on a 4-point Likert scale. In an earlier study, it had been shown that the parental rating has a highly significant association with the rating by the child's therapist [27]. For the assessment of behavior the parents completed the German version of Conners' Parent Rating Scale (short form) [28]. Each child was then assigned to a category indicating his or her main problem. If in the section of the questionnaire with the heading 'developmental problems' the item 'fluency problems, e.g. stuttering, cluttering' was marked as 'very severe' or 'severe', a child was classified as 
Table 1. Characteristics of the sample $(n=362)$

\begin{tabular}{|c|c|}
\hline Variable & $\%$ \\
\hline \multicolumn{2}{|l|}{ Age of child, years } \\
\hline $4-5$ & 13.2 \\
\hline $6-7$ & 37.5 \\
\hline $8-9$ & 32.8 \\
\hline $10-11$ & 16.5 \\
\hline \multicolumn{2}{|l|}{ Gender of child } \\
\hline Male & 66.9 \\
\hline Female & 33.1 \\
\hline \multicolumn{2}{|l|}{ Main problems of child } \\
\hline Fluency problems & 17.5 \\
\hline Language problems & 23.6 \\
\hline Speech problems & 8.9 \\
\hline Learning problems & 12.5 \\
\hline Behavioral problems & 3.9 \\
\hline Only slight problems & 33.6 \\
\hline \multicolumn{2}{|l|}{ Mother's education } \\
\hline $0-9$ years & 45.8 \\
\hline 10 years & 38.2 \\
\hline Qualification for university entrance & 16.0 \\
\hline \multicolumn{2}{|l|}{ Child's siblings } \\
\hline None & 10.9 \\
\hline 1 & 54.6 \\
\hline$>1$ & 34.5 \\
\hline \multicolumn{2}{|l|}{ Ethnicity } \\
\hline German & 91.3 \\
\hline Other & 8.7 \\
\hline \multicolumn{2}{|l|}{ Marital status of responding parent } \\
\hline Married & 85.2 \\
\hline Unmarried & 14.8 \\
\hline \multicolumn{2}{|l|}{ Place of residence (population) } \\
\hline$<1,000$ & 24.9 \\
\hline $1,000-25,000$ & 32.2 \\
\hline $25,001-100,000$ & 10.4 \\
\hline$>100,000$ & 32.5 \\
\hline
\end{tabular}

having 'fluency problems'. Children with pronounced grammar problems but without fluency problems were classified as having 'language problems' and those with distinct phonological difficulties but without fluency or language problems as having 'speech problems'. Children with predominantly behavioral problems (Conners' Parent Rating Scale score $>14$; clinical threshold) or learning problems and only slight speech-language abnormalities were classified as having 'behavioral problems' and 'learning problems', respectively, and those with only slight problems at the time of the survey as 'only slight problems'.

\section{Measures}

Perceived stigmatization was assessed using an adaptation (in German) of the Perceived Stigma Questionnaire by Link et al. [29]. We adapted the questionnaire to the situation of children with speech-language problems. For example, we changed the item 'Most people would willingly accept a former mental patient as a close friend' to 'I have the feeling that other children don't want my child as a friend'. We also added items concerning perceived understanding and support of both the child and the parents, and concerning stigma management by the parents. The parents were asked to rate the reactions of 3 different social groups (other children, other adults and family members), in each case considering only reactions related to their child's disability. Ratings were made on a 4-point Likert scale, ranging from strongly agree (0) to strongly disagree (3).

To improve the validity of the questionnaire we had asked experts to rate it. Twenty-eight experts (speech-language therapists, pediatricians, child and adolescent psychiatrists) rated each item on a 4-point scale to indicate whether the item provided useful information about stigmatization or support and whether it was clearly formulated. We then deleted or modified the least meaningful items.

The final version contained 58 items on perceived stigmatization and support (for sample items see the Appendix). The results reported here are confined to perceived stigmatization. The analyses are based on those 21 items that were formulated identically for the 3 social groups (other children, other adults, family members).

The questionnaire also contained items about the child's behavior and disabilities and the family's sociodemographic situation (see Sample section).

\section{Results}

About half of the parents indicated that their child had experienced rejection and exclusion because of his or her developmental abnormalities. They reported that stigmatization was usually by other children, but about $20 \%$ also felt there was a lack of understanding and acceptance of their child within their own family (table 2). About one third of the parents perceived stigmatization directed not only against their child but also against themselves. They reported that because of their child's developmental disorder others had been making disparaging remarks, had avoided contact with them and had said the parents were responsible for their child's developmental problems (table 3). As a reaction to stigmatizing remarks some parents had tried to play down their child's developmental problems or had limited their contact with others (table 4).

The impact of personal and environmental factors on the degree of stigmatization was assessed by calculating the relationship between the total score for stigmatization (stigmatization score-child, stigmatization scoreparent) and individual and socioeconomic variables. The total score reflects the average rating of the stigmatization items in the questionnaire. The range of the scores is $0-3$, corresponding to the coding of the items. The stigmatization score-child is the average of 15 items (5 items for each of the 3 social groups) and the stigmatization 
Table 2. Perceived stigmatization of speech-language-impaired children by other children, other adults or some family members (percent agreement)

\begin{tabular}{|c|c|c|c|c|}
\hline \multirow{2}{*}{$\begin{array}{l}\text { I have the feeling that because of my child's developmental } \\
\text { problems other children/other adults/some family members }\end{array}$} & \multicolumn{3}{|c|}{ Social group } & \multirow{2}{*}{$\begin{array}{l}\text { In at least one } \\
\text { social group }\end{array}$} \\
\hline & $\begin{array}{l}\text { other } \\
\text { children }\end{array}$ & $\begin{array}{l}\text { other } \\
\text { adults }\end{array}$ & $\begin{array}{l}\text { family } \\
\text { members }\end{array}$ & \\
\hline Tease my child & 23.8 & 3.6 & 6.9 & 32.3 \\
\hline Mock my child (for example, imitate him/her) & 18.6 & 2.5 & 4.4 & 28.0 \\
\hline Think my child is stupid & 16.6 & 12.9 & 6.4 & 22.5 \\
\hline Don't want my child as a friend/prefer not having my child around & 25.1 & 12.7 & 14.1 & 32.3 \\
\hline Avoid being with my child & 10.3 & 9.4 & 2.7 & 18.4 \\
\hline Mean percentage & 18.9 & 8.2 & 6.9 & 24.8 \\
\hline Percentage of parents agreeing with one or more of the statements & 39.7 & 24.1 & 21.6 & 49.7 \\
\hline
\end{tabular}

Agreement $=$ Strongly agree or agree

Table 3. Perceived stigmatization of the parents of speech-language-impaired children by other adults or by some family members (percent agreement)

\begin{tabular}{|c|c|c|c|}
\hline \multirow{2}{*}{$\begin{array}{l}\text { I have the feeling that because of my child's developmental problems } \\
\text { other adults/some family members }\end{array}$} & \multicolumn{2}{|c|}{ Social group } & \multirow{2}{*}{$\begin{array}{l}\text { In at least } \\
\text { one social } \\
\text { group }\end{array}$} \\
\hline & $\begin{array}{l}\text { other } \\
\text { adults }\end{array}$ & $\begin{array}{l}\text { family } \\
\text { members }\end{array}$ & \\
\hline Make disparaging remarks about us as parents & 13.0 & 12.2 & 20.3 \\
\hline Avoid having contact with us as parents & 10.0 & 6.4 & 13.7 \\
\hline Think we as parents are responsible for our child's developmental problems & 14.4 & 14.8 & 22.1 \\
\hline Mean percentage & 12.5 & 11.1 & 18.7 \\
\hline Percent agreement with one or more of the statements & 22.8 & 19.7 & 30.2 \\
\hline
\end{tabular}

Agreement $=$ Strongly agree or agree

Table 4. Stigma management by the parents of speech-language-impaired children in the presence of other adults or family members (percent agreement)

\begin{tabular}{|c|c|c|c|}
\hline \multirow[t]{2}{*}{ Reactions of the parents towards other adults/family members } & \multicolumn{2}{|c|}{ Social group } & \multirow{2}{*}{$\begin{array}{l}\text { In at least } \\
\text { one social } \\
\text { group }\end{array}$} \\
\hline & $\begin{array}{l}\text { other } \\
\text { adults }\end{array}$ & $\begin{array}{l}\text { family } \\
\text { members }\end{array}$ & \\
\hline \multirow{2}{*}{$\begin{array}{l}\text { I try to play down my child's developmental problems in front of } \\
\text { other adults/family members } \\
\text { I avoid contact with other adults/some family members because of } \\
\text { disparaging remarks about my child }\end{array}$} & 12.5 & 10.8 & 17.4 \\
\hline & 11.3 & 10.5 & 16.6 \\
\hline Mean percentage & 11.9 & 10.6 & 17.0 \\
\hline
\end{tabular}

Agreement $=$ Strongly agree or agree . 
score-parent of 6 items ( 3 items, 2 social groups) (for items see tables 2 and 3 ).

One-way analyses of variance were performed separately for the stigmatization score-child and the stigmatization score-parent with the factors type of disability, existence of behavioral problems, gender of the child, size of the town or city, ethnic identity, parents' marital status, mother's educational level and the covariate age of the child. The analyses yielded significant effects of type of disability on the stigmatization of the children $(\mathrm{F}=6.11$, $\mathrm{p}<0.001)$ and parents $(\mathrm{F}=2.869, \mathrm{p}=0.015)$. Subsequent analyses for each diagnostic group showed a significantly higher stigmatization score-child for children with predominantly fluency problems than for those with predominantly speech problems $(\mathrm{T}=3.341, \mathrm{p}<0.001)$ or only slight problems $(\mathrm{T}=3.870, \mathrm{p}<0.001)$. Similar differences were found between the children with predominantly behavioral problems and those with speech problems $(\mathrm{T}=2.801, \mathrm{p}=0.008)$ or only slight problems $(\mathrm{T}=$ 3.095, $\mathrm{p}=0.002$ ) (fig. 1). The existence of behavioral problems (Conners Parent Rating Scale score $>14$ ) had a pronounced effect on both the stigmatization score-child $(\mathrm{F}=45.367, \mathrm{p}<0.001)$ and the stigmatization scoreparent $(\mathrm{F}=24.622, \mathrm{p}<0.001)$. No influence on the extent of stigmatization was found for the gender or age of the child, ethnic identity, the size of the town or city, the parents' marital status or the mother's educational level.

\section{Discussion}

The results of our study give evidence that communication disabilities in children are stigmatizing marks and that the parents of children with speech-language disorders often perceive negative labeling of their child. Moreover, parents report stigmatizing attitudes not only in other children and other adults but also in members of their own family.

Evidence that children with speech-language disorders are at risk of being targets for victimization is provided in a study by Knox and Conti-Ramsden [30]. In that study, $36 \%$ of the children with specific language impairment were bullied at school compared to only $12 \%$ of their normally developing peers.

In the present study, we found evidence that the extent of perceived stigmatization depends on the type of speech-language impairment. The parents of children with predominantly fluency problems more often reported rejection of their child or disparaging remarks than did the parents of children with other speech-language

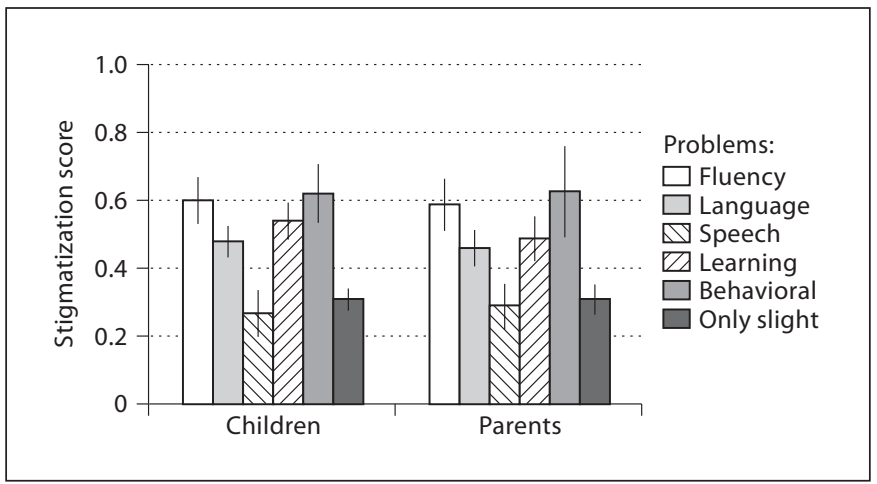

Fig. 1. Perceived stigmatization of children and their parents by the predominant type of problem (means and standard deviations of stigmatization scores).

problems. There appeared to be no influence of age or sex on environmental reactions. Furthermore, we did not find any evidence for a relationship between perceived stigmatizing labeling and the parents' marital status, the mother's educational level, ethnic identity or size of the town or city. The findings of other studies are conflicting regarding the association between the social situation of the family and perceived stigmatization. Consistent with our results, Lücke and Knölker [25] found no correlation between sociodemographic variables of the family and the stigmatization score in children and adolescents receiving psychiatric treatment. In contrast, Phelan et al. [26] reported that the more education mothers of psychiatric patients have the more stigmatization they perceive. At this stage, the impact of sociodemographic variables on the feeling of stigmatization in connection with developmental disabilities appears to be low.

In our study, we could demonstrate that children with speech-language problems and additional behavioral disorders are especially likely to experience negative remarks and rejection. The relationship between stigmatization and behavioral problems has been stressed by Shea and Wiener [31], who reported severe emotional distress and the development of 'social exile' resulting from negative labeling by peers at school in 4 boys with attention deficit hyperactivity disorder. According to Johnson et al. [32], boys with hyperactivity, poor social skills or general difficulties with social interactions are at a high risk of being bullied. Conduct problems make it difficult for the interaction partners to anticipate what will happen during the communication process, resulting in avoidance of contact and exclusion of the difficult child from the peer group. A survey of 1,055 pupils illustrates the relevance 
of behavioral problems for peer interactions [33]: the largest social distance was found from children with conduct disorders, followed by children with mental retardation.

But not only are behavioral problems a potential cause of stigmatization - they may also be the result of it. Carlton-Ford et al. [34] investigated the relationship between behavioral disturbances and social interactions in children with epilepsy. Their findings suggest that the children's behavioral problems were at least partially due to perceived stigmatization.

The mechanisms underlying an association of speechlanguage impairment, psychiatric disorders and stigmatization are not clear. Several patterns of relationship may be discussed. First, there could be a direct causal relationship between language disturbances, stigmatization and psychiatric disorders. Language plays a crucial role in interpersonal functioning, and limited abilities to express wishes, needs and emotions verbally and constraints in encoding verbal messages have a negative impact on interpersonal interactions. Communication partners may react with uncertainty and rejection, and the child could be at risk of becoming a target for stigmatization. The stigmatizing process stemming from poor communication skills might then result in psychiatric disorders with oppositional-aggressive behavior, withdrawn social style, social anxiety, or all three.

Second, stigmatization may be mediated by psychiatric or learning disorders. Ineffective verbal interactions might provoke frustration and lead to psychosocial difficulties with poor emotional regulation and behavioral control. Children with psychiatric disorders are generally at risk of experiencing exclusion and victimization [35]. Moreover, stigmatization might also be mediated by learning disorders. Longitudinal studies have shown that many children with speech-language disorders are dyslexic at school age [36]. Learning disabilities have an implication for peer acceptance and lead to a risk of being stigmatized [19, 20].

Third, stigmatization could be exclusively a consequence of behavioral and emotional problems and be independent of speech-language impairment. Several studies provide evidence for comorbidity of language and psychiatric disorders in children with communication disorders without there being a causal relationship [37, 38]. Language and psychiatric disturbances may both stem from a maturational lag of the brain but nevertheless be independent of each other.

Fourth, the great differences in the socioemotional adaptation of children with speech-language disorders suggests that there is not a simple causal relationship among poor language skills, psychiatric problems of an externalizing or internalizing nature and social exclusion and victimization. Speech-language disabilities, behavioral and emotional problems and stigmatization could be highly interrelated. Language problems might lead to psychosocial difficulties and stigmatizing processes and vice versa. The language, psychiatric and social difficulties could aggravate each other in the complex system of social interactions.

The involvement of parents in stigmatizing processes has been considered only rarely. One third of the parents in the present study reported perceiving stigmatization of themselves related to the developmental abnormalities of their child. They felt that other adults or some members of their family made disparaging remarks or restricted contact with them. In an earlier study we found that mothers of children with speech-language impairment often feel depressed (33\%), disappointed (25\%) or aggressive (14\%) as a consequence of their child's developmental disability [39]. However, it is not clear whether the negative emotional reactions of the mothers stem from stigmatization or are in fact not causally related to the pejorative labeling by the environment. Phelan et al. [26] examined the degree of social rejection of parents of patients with mental illness. They interviewed 156 parents of first-admission adolescent and adult psychiatric patients. About $50 \%$ of the parents said they kept their child's hospitalization secret, even if they did not perceive themselves as being involved in the stigmatization process. Expecting rejection and fearing it was the reason they gave for concealing the hospitalization. Family members with more education reported greater avoidance by others. Taken together, the findings show that there is a danger of parents being stigmatized because of the developmental disorder or mental illness of their child.

In the present study we also asked parents about how they reacted to stigmatizing attitudes. Some reported limiting contact with others or avoiding talking about their child's developmental disability as ways of preventing stigmatizing reactions. Similar coping strategies have been reported for children receiving psychiatric treatment and their parents [25]. Withdrawal and secrecy are typical stigma management strategies. But the effectiveness of such behavior is doubtful. Link et al. [29] investigated the effect of coping strategies in 164 psychiatric patients. Neither concealing of psychiatric treatment nor avoiding stigmatizing situations nor educating others about the nature of the illness diminished negative labeling and rejection. In fact, the authors concluded that 
these stigma management strategies seemed to make the situation worse rather than improving it.

There are several constraints on generalizing our findings. We recorded data about the parent's perception of stigmatization, but it is unclear whether the perception of the parents truly reflects stigmatization processes. However, perception and evaluation of the reactions of the environment is eminently critical for successful or failed coping with disabilities. Moreover, our response rate was $44 \%$. Hence our data do not permit a reliable assessment of the extent of perceived stigmatization. Even so, the results show that perceived stigmatization is a real problem in families of children with speech-language disorders.
As the feeling of being labeled is not uncommon, professionals should talk about stigmatization and discuss its consequences when counseling families of children with communication disturbances.

The relevance of stigmatization of children with speech-language disorders is, however, still largely unexplored territory. There have been very few studies on the incidence and consequences of negative labeling of such children. Therefore, an effort should be made to clarify the relevance of stigmatization of children with communication disorders and their families, and to prevent such stigmatization.

Appendix: Sample items from the questionnaire, complete section 'Reactions of family members' (translated from German)

Only reactions related to your child's developmental problems

\begin{tabular}{lll} 
During the last 3 months \\
\hline strongly agree & dis- & strongly \\
agree & agree & disagree
\end{tabular}

I have the feeling that members of my family prefer my child to other children in the family I have the feeling that members of my family give my child increased support

I have the feeling that all members of my family interact with my child in an unprejudiced way I have the feeling that all members of my family are very understanding of my child I have the feeling that members of my family mock my child (for example, imitate him/her) I have the feeling that members of my family think my child is stupid I have the feeling that members of my family think my child is just trying to attract attention I have the feeling that members of my family think my child just doesn't pay enough attention I have the feeling that members of my family prefer not to have my child around

I have the feeling that my child gets into arguments more often than other children because of his/her

developmental problems

I have the feeling that members of my family tease my child

I have the feeling that members of my family avoid being with my child

I have the feeling that all members of my family are very understanding of us as parents

I have the feeling that members of my family make disparaging remarks about us as parents

I have the feeling that members of my family avoid having contact with us as parents

I have the feeling that I can speak openly about my child's developmental problems to all family members

I have the feeling that members of my family think we are responsible for our child's developmental problems I try to play down my child's developmental problems in front of family members

I avoid contact with some family members because they make disparaging remarks about my child

$\begin{array}{llll}\square & \square & \square & \square \\ \square & \square & \square & \square \\ \square & \square & \square & \square \\ \square & \square & \square & \square \\ \square & \square & \square & \square \\ \square & \square & \square & \square \\ \square & \square & \square & \square \\ \square & \square & \square & \square \\ \square & \square & \square & \square \\ \square & \square & \square & \square \\ \square & \square & \square & \square \\ \square & \square & \square & \square \\ \square & \square & \square & \square \\ \square & \square & \square & \square \\ \square & \square & \square & \square \\ \square & \square & \square & \square \\ \square & \square & \square & \square \\ \square & \square & \square & \square \\ \square & \square & \square & \square\end{array}$

\section{References}

1 Beitchman JH, Wilson B, Brownlie EB, Walters $\mathrm{H}$, Lancee $\mathrm{W}$ : Long-term consistency in speech/language profiles. 1. Developmental and academic outcomes. J Am Acad Child Adolesc Psychiatry 1996;35:804-814.

2 Beitchman JH, Hood J, Inglis A: Psychiatric risk in children with speech and language disorders. J Abnorm Child Psychol 1990;18: 283-296.
3 Cantwell DP, Baker L: Prevalence and type of psychiatric disorder and developmental disorders in three speech and language groups. J Commun Disord 1987;20:151-160.

4 Goodyer IM: Language difficulties and psychopathology; in Bishop DVM, Leonard LB (eds): Speech and Language Impairments in Children: Causes, Characteristics, Intervention and Outcome. Hove, Psychology Press, 2001, pp 227-244.
5 Jerome AC, Fujiki M, Brinton B, James SL: Self-esteem in children with specific language impairment. J Speech Lang Hear Res 2002;45:700-714

6 Gallagher TM: Interrelationships among children's language, behavior, and emotional problems. Top Lang Disord 1999;19:1-15.

7 Rice ML, Sell MA, Hadley PA: Social interactions of speech- and language-impaired children. J Speech Hear Res 1991;34:1299-1307. 
8 Durkin K, Conti-Ramsden G: Language, social behavior, and the quality of friendships in adolescents with and without a history of specific language impairment. Child Dev 2007;78:1441-1457.

9 Clegg J, Hollis C, Mawhood L, Rutter M: Developmental language disorders - A followup in later adult life. Cognitive, language and psychosocial outcomes. J Child Psychol Psychiatry 2005;46:128-149.

10 Beitchman JH, Wilson B, Johnson CJ, Atkinson L, Young A, Adlaf E, Escobar M, Douglas L: Fourteen-year follow-up of speech/language-impaired and control children: psychiatric outcome. J Am Acad Child Adolesc Psychiatry 2001;40:75-82.

11 Brinton B, Fujiki M: Social competence in children with language impairment: making connections. Semin Speech Lang 2005;26: 151-159.

12 Goffman E: Stigma. Notes on the Management of Spoiled Identity. Englewood Cliffs, Prentice-Hall, 1963.

13 Link BG, Phelan JC: Conceptualizing stigma. Annu Rev Sociol 2001;27:363-385.

14 Link BG, Phelan JC: Stigma and its public health implications. Lancet 2006;367:528529.

15 McArdle E: Communication impairment and stigma; in Mason T, Carlisle C, Watkins C, Whitehead E (eds): Stigma and Social Exclusion in Healthcare. London, Routledge, 2001, pp 92-103.

16 Hinshaw S, Stier A: Stigma as related to mental disorders. Annu Rev Clin Psychol 2008;4: 367-393.

17 El-Badri S, Mellsop G: Stigma and quality of life as experienced by people with mental illness. Australas Psychiatry 2007;15:195-200.

18 Britten N, Wadsworth ME, Fenwick PB: Stigma in patients with early epilepsy: a national longitudinal study. J Epidemiol Commun Health 1984;38:291-295.
19 Espelage DL, Swearer SM: Research on school bullying and victimization: what have we learned and where do we go from here? School Psych Rev 2003;32:356-383.

20 Flynt SW, Morton RC: Bullying and children with disabilities. J Instruct Psychol 2004;31: 330-333.

21 Eisenberg ME, Aalsma MC: Bullying and peer victimization: position paper of the Society for Adolescent Medicine. J Adolesc Health 2005;36:88-91.

22 Scheithauer H, Hayer T, Petermann F: Bullying unter Schülern. Erscheinungsformen, Risikobedingungen und Interventionskonzepte. Göttingen, Hogrefe, 2003.

23 Klicpera BG, Klicpera C: Viktimisierung durch Gleichaltrige als Entwicklungsrisiko. Z Kinder Jugendpsychiatr Psychother 2001; 29:99-111.

24 Harris MJ, Milich R, Corbitt EM, Hoover DW, Brady M: Self-fulfilling effects of stigmatizing information on children's social interactions. J Pers Soc Psychol 1992;63:4150.

25 Lücke M, Knölker U: Zur Frage der Stigmatisierung von Patienten in einer stationären Einrichtung für Kinder- und Jugendpsychiatrie. Prax Kinderpsychol Kinderpsychiatr 1991;40:138-147.

26 Phelan JC, Bromet EJ, Link BG: Psychiatric illness and family stigma. Schizophr Bull 1998;24:115-126.

27 Limm H, von Suchodoletz W: Professionelle Unterstützungssysteme aus der Sicht von Eltern sprachentwicklungsgestörter Kinder. Frühförderung Interdisziplinär 1999;18:8491.

28 Steinhausen H-C: Psychische Störungen bei Kindern und Jugendlichen - Lehrbuch der Kinder- und Jugendpsychiatrie. München, Urban \& Schwarzenberg, 1993.

29 Link BG, Mirotznik J, Cullen FT: The effectiveness of stigma coping orientations: can negative consequences of mental illness labeling be avoided? J Health Soc Behav 1991; 32:302-320.
30 Knox E, Conti-Ramsden G: Bullying risks of 11-year-old children with specific language impairment (SLI): does school placement matter? Int J Lang Commun Disord 2003;38: $1-12$.

31 Shea B, Wiener J: Social exile: the cycle of peer victimization for boys with ADHD. Can J Sch Psychol 2003;18:55-90.

32 Johnson HR, Thompson MJJ, Wilkinson S, Walsh L, Balding J, Wright V: Vulnerability to bullying: teacher-reported conduct emotional problems, hyperactivity, peer relationship difficulties, and prosocial behaviour in primary school children. J Educ Psychol 2002;22:553-556.

33 Nickel S: Gesellschaftliche Reaktionen auf Menschen mit (geistiger) Behinderung in der Kinder- und Jugendliteratur. Behindertenpädagogik 1999;38:381-404.

34 Carlton-Ford S, Miller R, Nealeigh N, Sanchez N: The effects of perceived stigma and psychological over-control on the behavioural problems of children with epilepsy. Seizure 1997;6:383-391.

35 Hinshaw SP: The stigmatization of mental illness in children and parents: developmental issues, family concerns, and research needs. J Child Psychol Psychiatry 2005;46: 714-734.

36 Larney R: The relationship between early language delay and later difficulties. Early Child Dev Care 2002;172:183-193.

37 von Suchodoletz W, Keiner T: Psychiatrische Aspekte bei sprachgestörten Kindern. Pädiatr Praxis 1998;54:395-402.

38 Beitchman JH, Cohen N, Konstantareas MM, Tannock R: Language, Learning, and Behavior Disorders: Developmental, Biological, and Clinical Perspectives. New York, Cambridge University Press, 1996.

39 Limm H, von Suchodoletz W: Belastungserleben von Müttern sprachentwicklungsgestörter Kinder. Prax Kinderpsychol Kinderpsychiatr 1998;47:541-551. 